\title{
Landfill Sites Identification Using GIS and Multi-Criteria Method: A Case Study of Intermediate City of Punjab, Pakistan
}

\author{
Adeel Ahmad1, Umar Javaid1, Muhammad Asif Javed1, Sajid Rashid Ahmad1, \\ Muhammad Abbas Jaffri ${ }^{2}$, Mudassar Ashfaq ${ }^{3}$ \\ ${ }^{1}$ College of Earth and Environmental Sciences, University of the Punjab, Lahore, Pakistan \\ ${ }^{2}$ MM Pakistan (Pvt.) Limited, Lahore, Pakistan \\ ${ }^{3}$ Ministry of Rural Affairs, Al-Dulemia, Saudi Arabia \\ Email: adeal.gis@gmail.com
}

Received 8 January 2016; accepted 16 February 2016; published 19 February 2016

Copyright (C) 2016 by authors and Scientific Research Publishing Inc.

This work is licensed under the Creative Commons Attribution International License (CC BY). http://creativecommons.org/licenses/by/4.0/

(c) (i) Open Access

\section{Abstract}

Escalation in population over time triggered the abrupt exploitation of natural resources for human survival trough industrialization that ultimately caused splendid increase in the waste generation. This industrial development resulted in the migration of rural community toward urban areas. Management of urban waste is a great challenge for the urban administration. However, technologies have been developed to manage the waste in environmental friendly and sustainable manner. Sanitary landfill sites are one of the latest methods of disposing the municipal solid waste in an environment friendly and sustainable manner. Government and administrative authorities are adopting this technology for the management of urban solid waste. Present study is about identifying landfill sites for the Sahiwal city with an area of 1160 square kilometer and projected population of 1.57 million persons in 2016. Geographical Information System (GIS) is used for the identification of appropriate landfill site (LFS) that can fulfill the need of city in future and is selected based on the sustainable and eco-friendly criteria. The criteria are developed keeping in view the proximity from several land-use features i.e. water bodies, roads, settlements, agricultural land, bare land and existing disposal sites. The weights of the criteria are quantified using pair-wise comparison method in Analytic Hierarchy Process (AHP). The weights are incorporated in GIS spatial data environment and are assigned to proximity threshold of each criterion. Ultimately a map for each criterion is developed highlighting suitable, least suitable, less suitable and un-suitable areas with respect to each specific criterion. These maps are spatially overlaid which result in a final map that identifies most suitable landfill sites for solid waste disposal. The five identified sites are then prioritized based on their distances from the city center and area available. All identified sites are on the bare land and contain considerable buffer from environmentally sensitive receptors. 


\section{Keywords}

\section{Urbanization, Urban Waste, Landfill Site (LFS), GIS, Analytic Hierarchy Process (AHP)}

\section{Introduction}

Densely populated areas of the world are usually subjected to more concerns relative to less populated places. One of these concerns is the solid waste management which is widely practiced through landfill method in developed and developing countries. The selection of LFS is a challenging process as its impact on economy, surroundings and health are numerous. This problem of waste management is more severe in developing countries because of huge population, urban migration, inappropriate planning and deficiency of sufficient resources etc. [1]. More space of land will be occupied by the landfill sites after every few years as there is continues increase in waste generation due to increase in population [2]. A suitable selection of LFS is very important as it should pose no harm to environment and ensures long life cycle [1].

Appropriate selection of landfill sites can be done using GIS tools and techniques as it tolerates correct processing of geospatial data retrieved through different sources and analyzes provided information to deliver possible solutions of the problem [2]. The capability of GIS to process and analyze spatial data is impressively time-efficient as compared to the manual selection of landfill sites [3]. An effective decision making can be done by the various authorities with the help of spatial characteristics of GIS.

Previously, GIS techniques are not in common use but now the application of GIS techniques has spread in various disciplines and serving as an integrated approach inside those disciplines [4]. Incorporating different factors like hydrology, environmental, socioeconomic, land-use make it possible to select an ideal landfill location for an area and, aimed at this, Multi-Criteria analysis or approach have to be used with GIS combination. Multi-Criteria Method can assign different weights to the landfill factors while the manipulation of the spatial data based on the assigned weights to landfill factors is to be made by GIS [1].

This study depicts a spatial model for LFS selection in combination with Multi-Criteria approach in which different site selection parameters are used i.e. proximity from environmentally sensitive receptors, residential areas, land-use existing dumping sites, roads accessibility etc.

\section{Analytical Hierarchy Process}

The most widely used AHP Multi Criteria approach has been developed by a renowned scholar the Thomas L. Saaty. This technique is extensively used in world for effective decision making purposes [5]-[7]. This technique involves a mechanism to determine the relative weight of multiple criteria in comparison to each criterion. Priorities of the criterion on the basis of their importance are to be defined by the decision makers or experts in the absence of any quantitative ratings. Pair wise comparison matrix is used to determine the relative importance of each factor on which basis a number on scale is assigned to each factor. Weight and scores of each criterion among each other is achieved by the Paired comparison matrix [8].

AHP involves the following step-wise processes:

- $\quad$ Selection of criterion

- Use of paired comparison matrix for setting priority or weighting of criterion

- Pair wise comparison of options on each criterion

- For each option to get an overall score

AHP is quite helpful in solving the complex sustainability issues and the difficulties regarding the decisions which are decomposed into small components and are organized hierarchically. Paired comparison approach is considered as most reliable technique because each individual trade-off is included by the decision makers which increase the accuracy of the process and results.

\section{Materials and Method}

\subsection{Study Area}

Sahiwal is densely populated city located between Ravi and Sutlej Rivers in the south east of Punjab. The fam- 
ous archaeological site Harappa which was built by 2600 BCE is about $35 \mathrm{Km}$ in the west of Sahiwal city. Geographically Sahiwal city is located between $30^{\circ} 40^{\prime} 0^{\prime \prime}$ North, $73^{\circ} 6^{\prime} 0^{\prime \prime}$ East and it is 500 feet above sea level. According to 1998 census population of the Sahiwal Tehsil were 1,057,837 which have been projected to 270,269 in 2012 as per 2.22\% growth rate. Sahiwal Tehsil is comprised of 52 Union councils with total area of 1610 Sq. $\mathrm{Km}$. Climatically it is hot region with fertile soil and $2000 \mathrm{~mm}$ Average rainfall [9]. Location and study area of the research is shown in Figure 1.

\subsection{Objectives}

The objectives of this study are:

- To obtain criteria weights through pair-wise comparison matrix for LFS identification

- To propose landfill sites for the study area using spatial techniques in GIS

\subsection{Methodology}

Selection of LFS depends on many factors or criteria depending on local conditions of the area. On the basis of

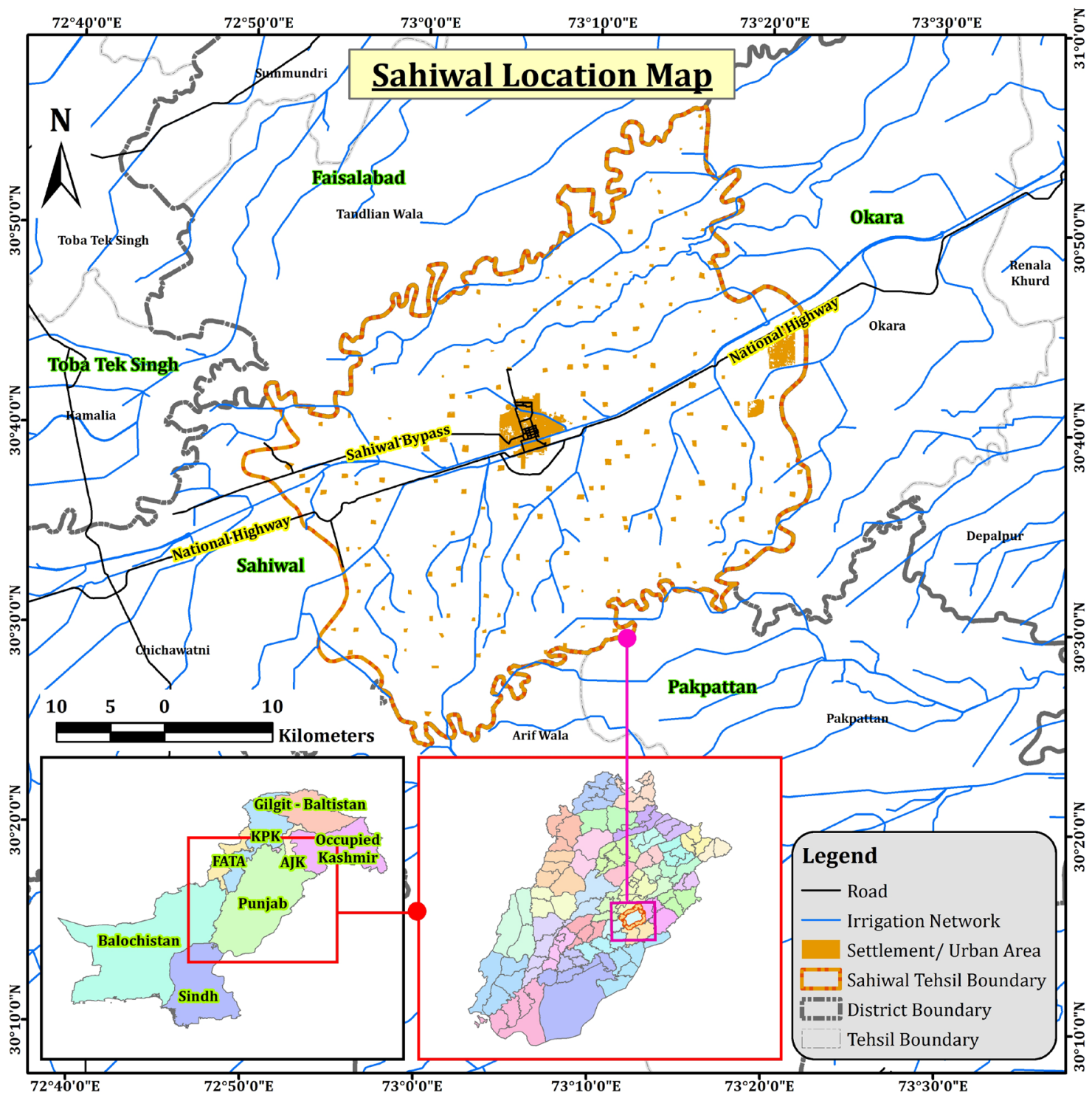

Figure 1. Location map of study area. 
previous studies and experts' consensus, six criteria based on the proximity from different land-use features which plays significant role in landfill site evaluation were considered. In this study, criteria selected for LFS identification were water body, bare land, agriculture, built up, road network and existing landfill site. Complete land-use data of Sahiwal city was obtained by Punjab Municipal Development Fund Corporation in vector form [9]. As the analysis demands the data up to the Tehsil level so the road network data up to the Tehsil level was digitized using ArcGIS Software.

Landsat-5 TM image, WRS-2 reference system, path 149, row 39 of 20-03-2011 was acquired through USGS online data facility. The image was then classified by performing the supervised classification using maximum likelihood algorithm in ERDAS Imagine and through this classification the land-use of buildup area (settlements), agricultural area and bare land were extracted. Vectorization of this data has been done to execute different analysis in GIS environment.

The methodological flowchart in Figure 2 presents an insight to the methods and techniques used in identifying the suitable sites for LFS.

AHP technique was used to define the weights and score of each criterion used in the evaluation of suitable location for LFS. Importance of each criterion over the others is decided by the consensus of experts. Scores and Weights of each criterion were calculated by the paired comparison matrix will be further used as input in raster calculator to evaluate or determine the unsuitable and potential landfill sites.

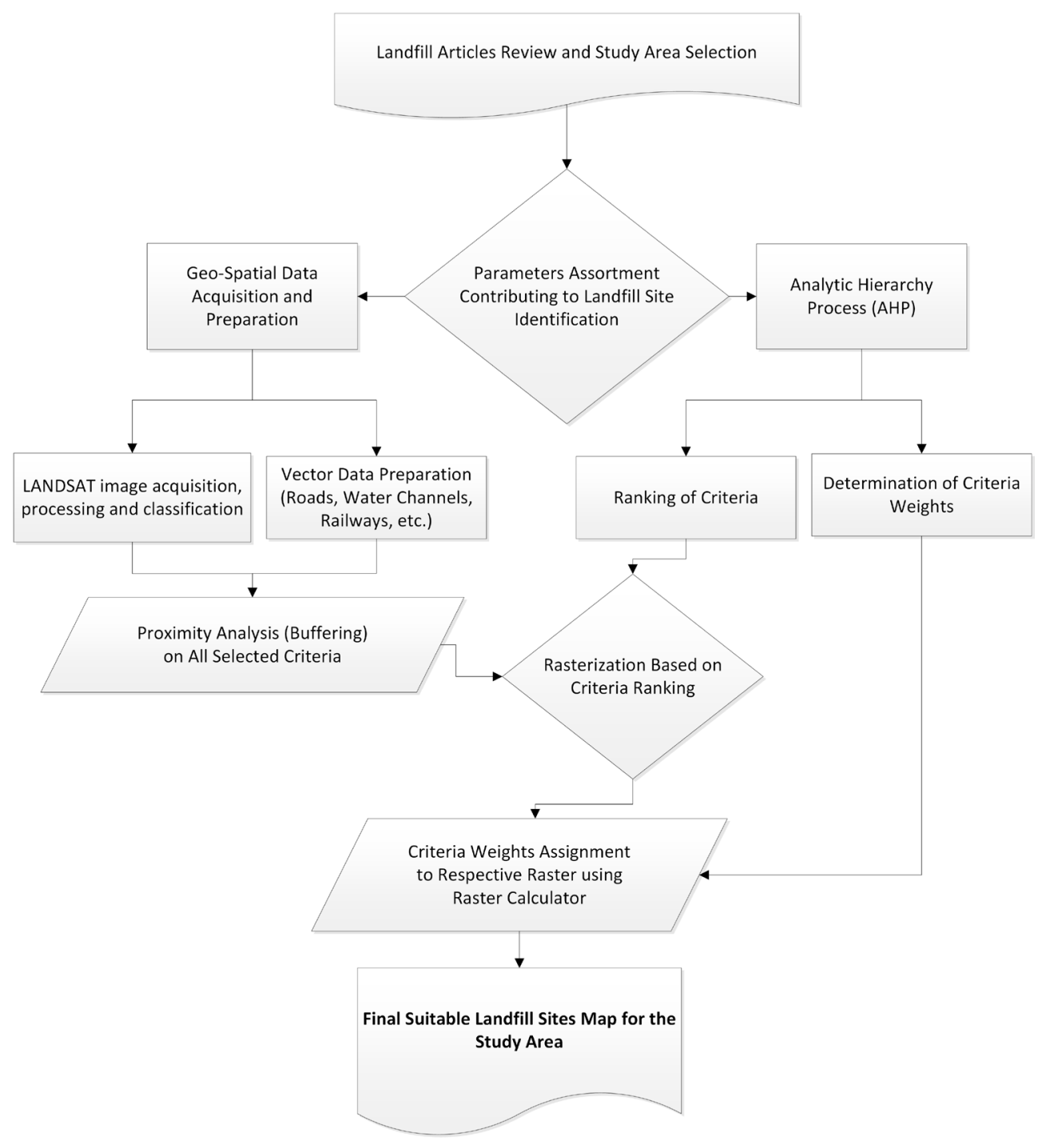

Figure 2. Flowchart of methodology. 


\section{Determination of Criteria Weights}

Pair wise comparison analysis which is a part of Analytical Hierarchy is being performed in Microsoft Excel by which score and weight of each criterion has been determined. The weights of the criteria were calculated using AHP and results are presented in Table 1. Table shows that bare land gained maximum weightage among all other variables which indicate that bare land is the most suitable option for proposing a new LFS. The value of consistency ratio (CR) for pair wise comparison was 0.019 which indicates that the comparison was relatively consistent and no further correction is required [7].

Paired comparison method provides a Ratio matrix which produces the output in the form of weights by using a scale ranges from 1 to 9 as shown in Table 2.

\section{Results and Discussion}

A chain of analysis has been performed to evaluate the suitability of LFS. Water body, road network, existing landfill sites built-up, settlements, agriculture and barren land classes were buffered in order to define the most suitable, suitable and unsuitable areas. After applying buffers on different classes, rasterization process has been done to perform Multi-Criteria analysis using the Analytical Hierarchy Process (AHP) Technique.

\subsection{Road Network}

$1000 \mathrm{~m}$ and above distance was set as a suitable distance by the LFS to the road, $500 \mathrm{~m}$ as least suitable and less then $250 \mathrm{~m}$ is considered as unsuitable distance from road to LFS. Figure 3 shows Reclassified Road Buffer Map.

Table 1. Pair-wise comparison method using AHP.

\begin{tabular}{|c|c|c|c|c|c|c|c|c|}
\hline $\begin{array}{l}\text { Pair-Wise Comparison } \\
\text { Method (AHP) }\end{array}$ & $\begin{array}{l}\text { Existing } \\
\text { Landfill } \\
\text { Sites }\end{array}$ & Built-Up & $\begin{array}{l}\text { Road } \\
\text { Network }\end{array}$ & Bare Land & $\begin{array}{l}\text { Water } \\
\text { Body }\end{array}$ & $\begin{array}{l}\text { Agricultural } \\
\text { Land }\end{array}$ & $\begin{array}{l}\text { Nth } \\
\text { Root of } \\
\text { Product }\end{array}$ & $\begin{array}{l}\text { Priority } \\
\text { Vector }\end{array}$ \\
\hline Existing Landfill Sites & 1.000 & 1.000 & 3.000 & 0.200 & 3.000 & 2.000 & 1.238 & 0.138 \\
\hline Built-Up & 1.000 & 1.000 & 0.500 & 0.110 & 0.330 & 0.500 & 0.457 & 0.051 \\
\hline Road Network & 0.333 & 2.000 & 1.000 & 0.200 & 2.000 & 7.000 & 1.109 & 0.124 \\
\hline Bare Land & 5.000 & 9.000 & 5.000 & 1.000 & 8.000 & 9.000 & 5.030 & 0.562 \\
\hline Water Body & 0.333 & 3.000 & 0.500 & 0.125 & 1.000 & 0.500 & 0.561 & 0.063 \\
\hline Agricultural Land & 0.500 & 2.000 & 0.143 & 0.110 & 2.000 & 1.000 & 0.562 & 0.063 \\
\hline SUM & & & & & & & 8.957 & 1 \\
\hline SUM & 8.166 & 18.000 & 10.143 & 1.745 & 16.330 & 20.000 & & \\
\hline $\mathbf{S U M} * \mathbf{P V}$ & 1.129 & 0.918 & 1.256 & 0.980 & 1.023 & 1.255 & & \\
\hline Lambda max & 6.560 & & & & & & & \\
\hline CI & 0.112 & & & & & & & \\
\hline CR & 0.019 & & & & & & & \\
\hline
\end{tabular}

Table 2. Scale ranges of weights for pair wise comparison method.

\begin{tabular}{ll}
\hline 1 & Equally preferred \\
2 & Equally to moderately preferred \\
3 & Moderately preferred \\
4 & Moderately to strongly preferred \\
5 & Strongly preferred \\
6 & Strongly to very strongly preferred \\
7 & Very strongly preferred \\
8 & Very to extremely strongly preferred \\
9 & Extremely preferred \\
\hline
\end{tabular}




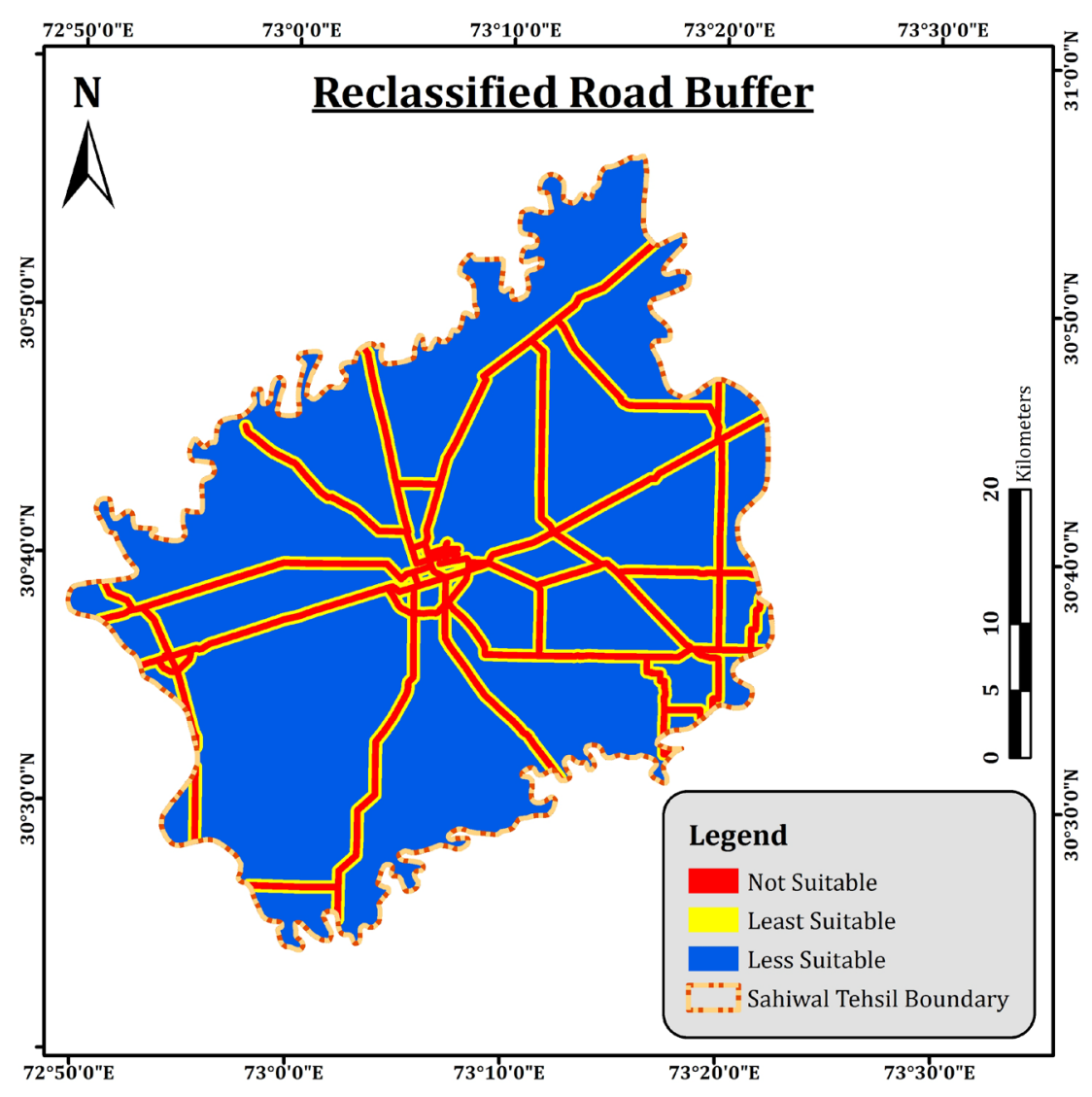

Figure 3. Reclassified road buffer map.

\subsection{Water Body}

Ground and surface water is directly affected by the landfill or dumping site through the leachate contamination, which can cause detrimental health impacts. Keeping in view the importance of this parameter for LFS evaluation by considering the distance less than $250 \mathrm{~m}$ of water body from LFS as unsuitable, $500 \mathrm{~m}$ least suitable, 75 $\mathrm{m}$ distance less suitable and distance of $1000 \mathrm{~m}$ and above as a suitable. Figure 4 show Water Body Reclassified Map.

\subsection{Built-Up Area}

Lives of peoples residing near by the landfill site may be affected in many ways, so this factor is always kept in focus while proposing a new landfill site, either it is at sufficient distance from residential areas. Here the area within the City boundary or urban limits is considered unsuitable for this kind of development. $125 \mathrm{~m}$ unsuitable 250 least, 375 less, 500 more suitable. Figure 5 shows Reclassified Settlement Buffer Map.

\subsection{Existing Dumping Site}

A well spatial distribution pattern must be kept in mind while proposing a new location by considering the effect or coverage area of existing one. Therefore the areas which are farther away from the existing dumping site are considered as most suitable. A distance of $1500 \mathrm{~m}$ and above from existing LFS is regarded as suitable, distance of $1000 \mathrm{~m}$ is less suitable and below $500 \mathrm{~m}$ are taken as least suitable for LFS development. Figure 6 shows the Reclassified Existing LFS Buffer Map.

\subsection{Barren and Agricultural Land}

Usually barren and agricultural land exists outside the urban limits and development in these areas has less impact 


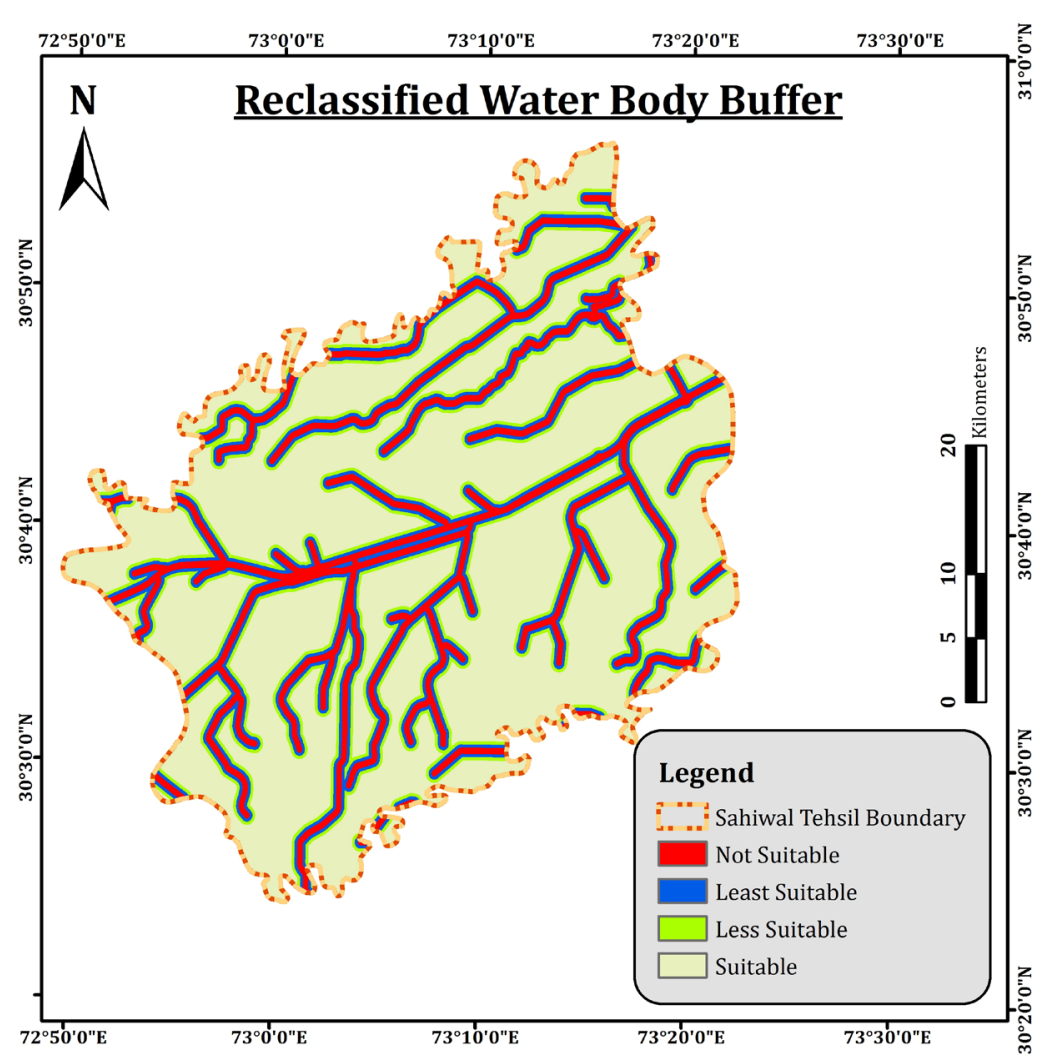

Figure 4. Water body reclassified map.

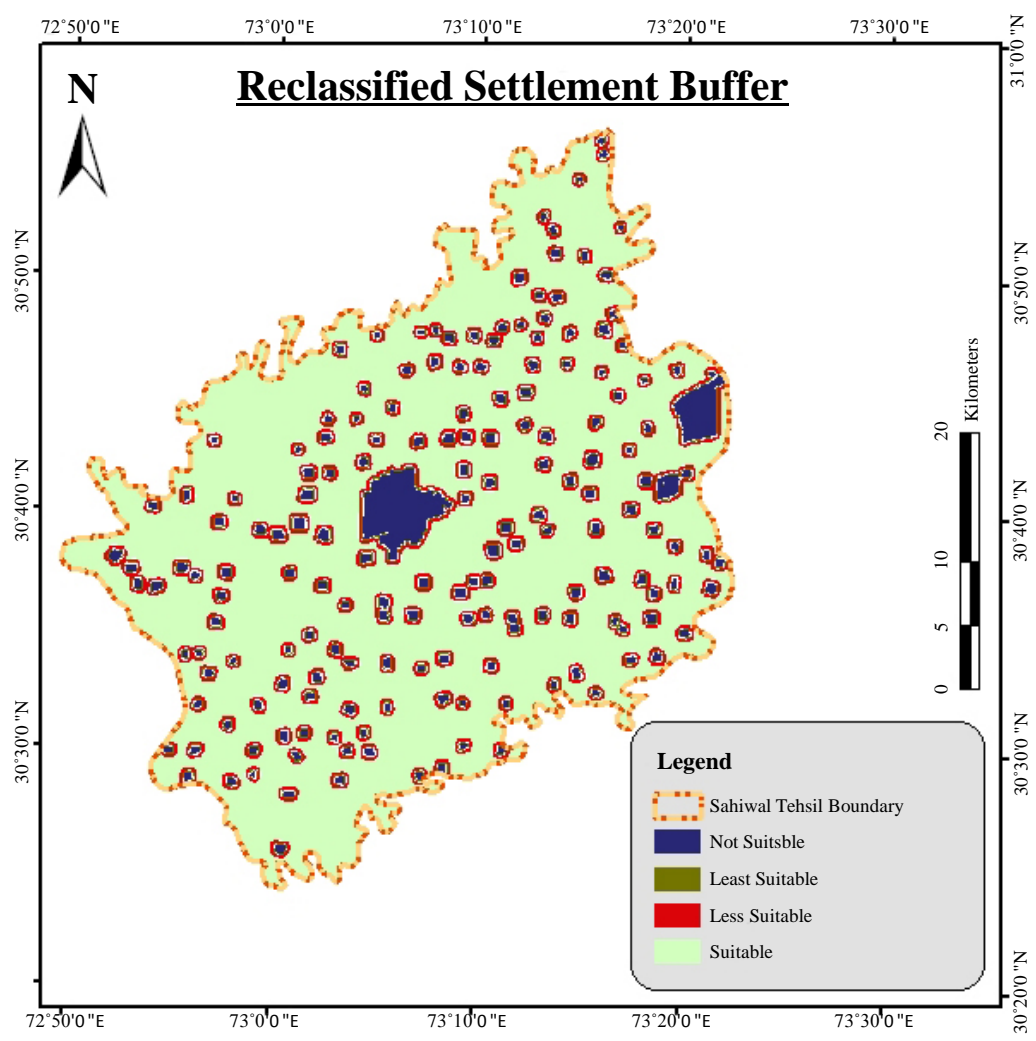

Figure 5. Reclassified settlement buffer map. 
on the environment and residents of the city, so these lands are considered as suitable for LFS development as shown in Figure 7 and Figure 8 shows Reclassified Bare and Agricultural Land Buffer respectively.

After applying the buffer on all of these criteria according to their respective suitability ranges, these classes were rasterized and then all of these classes were overlaid in raster calculator tool in ArcGIS software. Each of the criteria was multiplied by its weight and then took a sum of all these products. By these calculations suitable locations for landfill sites were obtained as shown in Figure 9.

\section{Conclusion}

Through the analysis of multiple parameters layers, the landfill sites were identified and then prioritized. Some specific parameter layers were buffered using proximity analysis in GIS software to determine the suitable and unsuitable areas and reclassified afterwards. Reclassified layers were given weights that were determined first using pair-wise comparison method in AHP which ultimately yielded a final map showing sites best suitable for solid waste landfill. The result revealed 5 sites suitable for landfill and out of those six suitable sites from the study area and out of those three landfill sites were preferred based on landfill site's area and access from the main city area. Three landfill sites were identified more suitable shown as LFS-1, LFS-2 and LFS-3 in Figure 9.

\section{Recommendation}

It is recommended that AHP technique incorporated with weighted overlay raster analysis should be used further for landfill sites identification in different dense populated cities of Pakistan as it is needed to combat the challenges of solid waste disposal due to huge increase in population growth and also because this technique put forward a solid, time efficient and cost effective method for landfill site identification. It is the need to develop a GIS model for the same procedure that will make it easy for others to produce results in an efficient way.

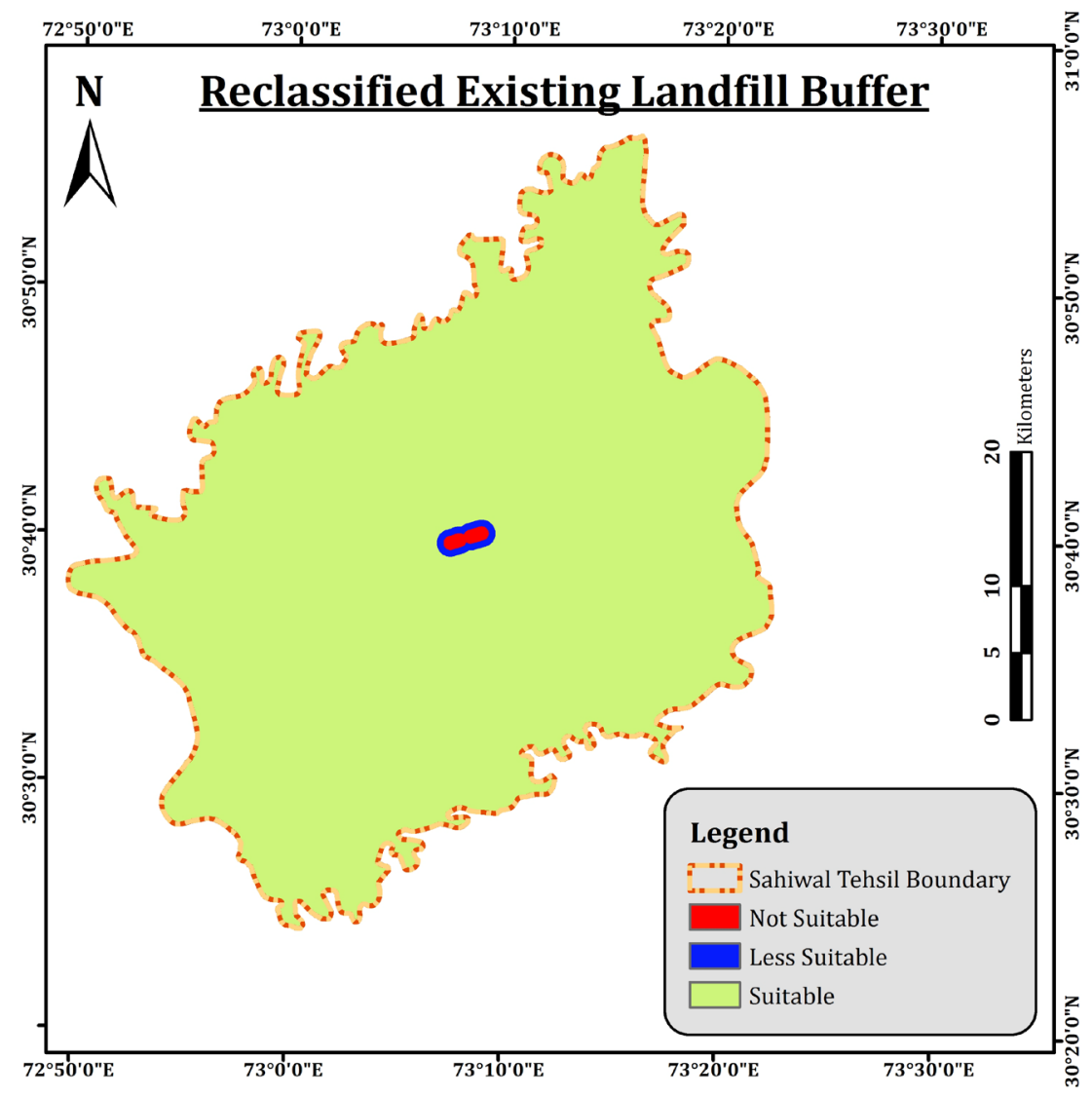

Figure 6. Reclassified existing landfill site map. 


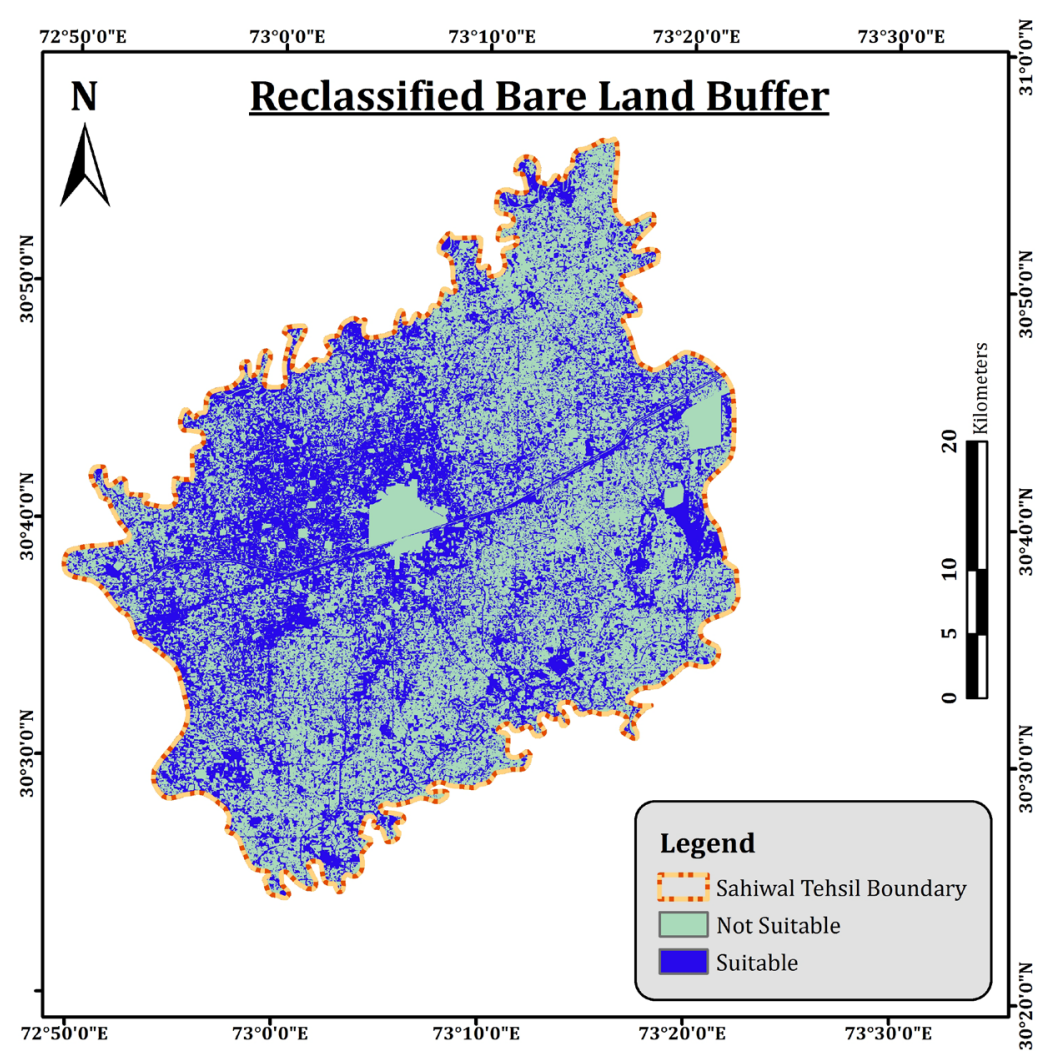

Figure 7. Reclassified bare land buffer.

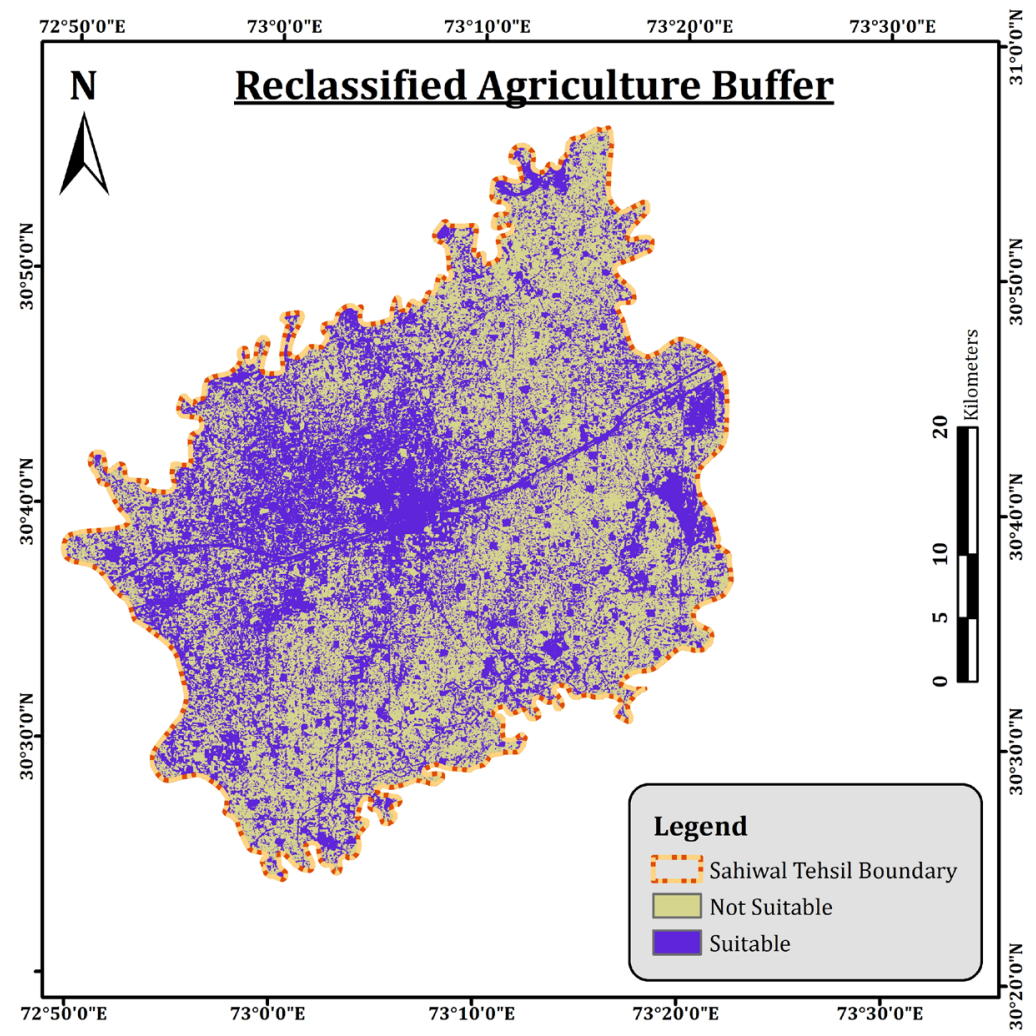

Figure 8. Reclassified agricultural buffer map. 


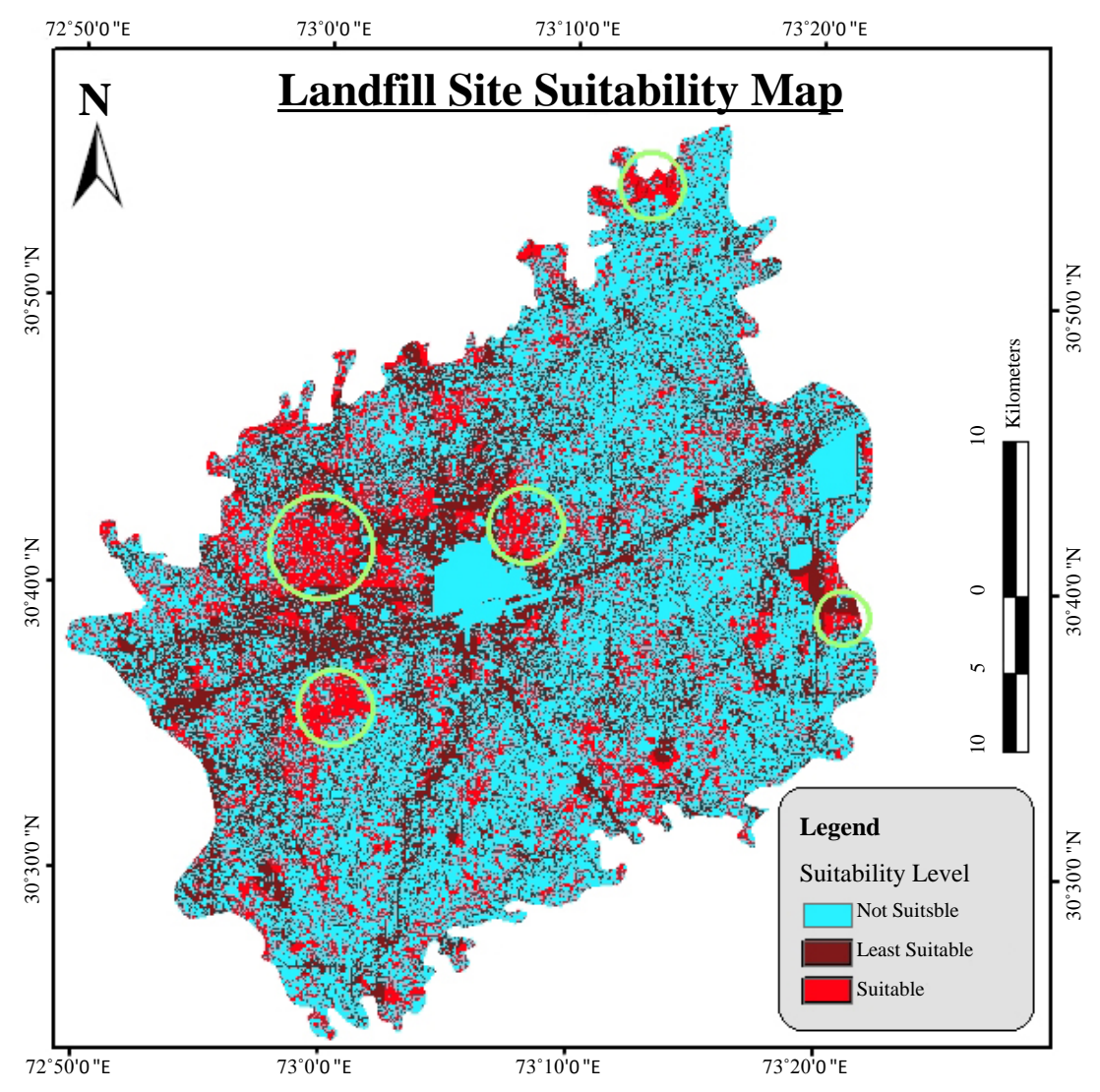

Figure 9. Landfill site suitability map.

Hence, AHP technique is the most appropriate method or approach to find the suitability of anything by resolving the complex issues.

\section{References}

[1] Mornya, A., Majid, R. and Yola, L. (2010) Identification of Landfill Sites by Using GIS and Multi-Criteria Method in Batam, Indonesia.

http://www.academia.edu/545126/Identification_of_Landfill_Sites_by_Using_GIS_and_Multi-Criteria_Method_in_Ba tam_Indonesia

[2] Amakihe, E. (2011) Geographic Information System (GIS) as a Decision Support Tool for Selecting Potential Landfill Sites. Novia University of Applied Sciences, Vassa.

[3] Thoso, M. (2007) The Construction of a Geographic Information System (GIS) Model for Landfill Site Selection. University of the Free State, Bloemfontein.

[4] Cummins, V., et al. (2002) A New Approach to Landfill Site Selection in Ireland using GIS Technology. Cork, Ireland.

[5] Saaty, T.L. (1977) A Scaling Method for Priorities in a Hierarchical Structure. Journal of mathematical psychology, 15, 234-281. http://dx.doi.org/10.1016/0022-2496(77)90033-5

[6] Saaty, T.L. (1986) Axiomatic Foundation of the Analytic Hierarchy Process. Management Sciences, 32, 841-855. http://dx.doi.org/10.1287/mnsc.32.7.841

[7] Saaty, T.L. (1990) How to Make a Decision: The Analytical Hierarchy Process. European Journal of Operational Research, 48, 9-26. http://dx.doi.org/10.1016/0377-2217(90)90057-I

[8] Office of the Deputy Prime Minister, G. U. (2004) DTLR Multi-Criteria Analysis Manual. http://www.communities.gov.uk/index.asp?id=1142251

[9] PMDFC (Punjab Municipal Development Fund Company) (2011) Sahiwal Town Status Report. Lahore, Punjab: PMDFC. 